\title{
Safety concerns with human papilloma virus immunization in Japan: Analysis and evaluation of Nagoya City's surveillance data for adverse events
}

See articles in Japan Journal of Nursing Science

DOI: 10.1111 /jins. 12258

Letter to the editor: Safety concerns with human papilloma virus immunization in Japan: Analysis and evaluation of Nagoya City's surveillance data for adverse events

Sadao Suzuki

DOI: $10.1111 /$ jjns. 12275

Authors' response to letter to the editor: Safety concerns with human papilloma virus immunization in Japan: Analysis and evaluation of Nagoya City's surveillance data for adverse events

Yukari Yaju and Hiroe Tsubaki

DOI: $10.1111 /$ jjins. 12282

Editor's Reply to the Letter to the Editor of Dr. Suzuki

William L. Holzemer

\author{
Yukari YAJU $\oplus^{1}$ and Hiroe TSUBAKI ${ }^{2}$ \\ ${ }^{1}$ Department of Statistics, Graduate School of Nursing Science, St. Luke's International University and ${ }^{2}$ The Institute of Statistical \\ Mathematics, Tokyo, Japan
}

\begin{abstract}
Aim: To assess the safety of human papilloma virus (HPV) vaccines by using data from the "Nagoya City Cervical Cancer Immunization Program Survey".

Methods: Unadjusted odds ratios (OR) were calculated between HPV-vaccinated cases and un-vaccinated controls. Age-stratified analyses were performed to evaluate the interaction between age and events. Adjusted ORs were also estimated with multiple logistic regression models.

Results: In the 15-16-year-old group, the unadjusted ORs were significantly higher for symptoms of memory impairment, dyscalculia, and involuntary movement. The age-adjusted multivariate analyses demonstrated that the vaccinated cases were less likely than the unvaccinated controls to have experienced symptoms in almost all symptoms, except for two symptoms such as involuntary movement and weakness. However, study period-adjusted multivariate analyses demonstrated that the vaccinated cases were significantly more likely than un-vaccinated controls to have experienced symptoms of memory impairment and involuntary movement.

Conclusions: Based on our analysis using data from the Nagoya City surveillance survey, a possible association between HPV vaccination and distinct symptoms such as cognitive impairment or movement

Correspondence: Yukari Yaju, Graduate School of Nursing Science, St. Luke's International University, 10-1 Akashi-cho, Chuoku, Tokyo 104-0044, Japan. Email: y-yaju@slcn.ac.jp

Received 2 October 2018; accepted 11 December 2018.

[Correction added on 14 August 2019, after first online publication: Statement to link the related Letter to the Editor articles has been inserted for cross-referencing purposes.]


disorders exists. A consistent causal relationship between HPV vaccination and these symptoms remains uncertain. However, given the seriousness of symptoms, we believe that a more comprehensive and largescale study is essential to confirm the safety of HPV vaccination.

Key words: adverse events, human papilloma virus, surveillance, vaccine.

\section{INTRODUCTION}

\section{Introduction of human papilloma virus vaccination}

Vaccines against the human papilloma virus (HPV) initially were introduced into public use with the 2006 European approval of the quadrivalent vaccine and the subsequent 2007 approval of the bivalent vaccine. In June, 2006, the Food and Drug Administration in the USA approved the quadrivalent vaccine and the Advisory Committee on Immunization Practices recommended routine HPV vaccination for girls (Markowitz et al., 2007). By August, 2014, 58 countries had introduced the HPV vaccine into their national immunization program (World Health Organization, 2014). As of November, 2015, >63 million and 19 million persons worldwide were estimated to have been vaccinated with the quadrivalent and bivalent vaccine, respectively (European Medicines Agency, 2015).

These vaccines also were approved for use in Japan in October, 2009 for the bivalent vaccine and July, 2011 for the quadrivalent vaccine. After a HPV vaccine promotion campaign, the vaccines were included in the Japanese vaccination program for girls aged $12-16$ years in April, 2013. Within 3 months of formal designation as a routine vaccine, however, the Ministry of Health, Labour and Welfare issued a nationwide notice to withhold recommending HPV vaccination in June, 2013 (Ministry of Health, Labour \& Welfare, 2013). The measures that were taken by the Japanese Government triggered domestic and international controversy.

\section{Case reports of adverse events}

Kinoshita et al. (2014) reported 40 girls who were aged 11-17 years developed several symptoms after HPV vaccination. The authors referred to these symptoms as "complex regional pain syndrome" (CRPS) and "postural orthostatic tachycardia syndrome" (POTS), which were interpreted as peripheral autonomic disorders. Nishioka, Yokota, and Matsumoto (2014) proposed the term "HPV vaccination-associated neuroimmunopathic syndrome" (HANS) in order to refer to a variety of symptoms that occur after HPV vaccination and created preliminary diagnostic criteria in 2014 (Nishioka, Yokota, \& Matsumoto, 2014; Yokota, Kuroiwa, Nakamura, Nakajima, \& Nishioka, 2015). Doctors and researchers who have examined patients with post-HPV vaccination symptoms highlighted characteristic symptoms. The reported serious adverse events included diverse, complex, multisystem symptoms, such as: seizures; impaired consciousness; systemic pain including headache, myalgia, arthralgia, back pain, and other pain; motor dysfunction such as paralysis, muscular weakness, exhaustion, and involuntary movement; autonomic symptoms including dizziness, hypotension, tachycardia, and diarrhoea; endocrine disorders such as menstrual abnormality and menorrhagia; severe photophobia and hyperacusis; sleep disorders; and higher brain dysfunction and cognitive impairments including impaired memory, disorientation, and poor concentration (Kinoshita et al., 2014; Nishioka, Yokota, \& Matsumoto, 2014; Yokota, Kuroiwa, Nakamura, Nakajima, \& Nishioka, 2014). Many of these symptoms overlap with CRPS, POTS, chronic fatigue syndrome (CFS) and fibromyalgia syndrome. Furthermore, in some cases, these symptoms impaired learning ability and resulted in extreme fatigue and decreased motivation, having a negative impact on everyday life (Kinoshita et al., 2014).

Blitshteyn (2014) from the USA reported six patients who developed POTS following HPV vaccination. Brinth, Theibel, Pors, and Mehlsen (2015) from Denmark presented 53 patients with suspected side-effects to the quadrivalent HPV vaccine and reported that all the patients had symptoms that were consistent with pronounced autonomic dysfunction.

In recent years, Ozawa, Hineno, Kinoshita, Ishihara, and Ikeda (2017) described a case series of Japanese girls who were affected by suspected HPV vaccinerelated symptoms. They concluded that HPV vaccination was related to the transiently high prevalence of multiple symptoms, including CRPS and autonomic and cognitive dysfunction. Furthermore, Chandler et al. (2017) published a novel approach to case series identification for thorough signal evaluation by using datadriven exploratory cluster analysis of HPV vaccine 
adverse event reports. They reported that the proportional reporting ratio of the combination of adverse events terms (headache and dizziness with either syncope or fatigue), comparing HPV vaccine reports with non-HPV vaccine reports was 2.44 (95\% confidence interval [CI]: 2.07-2.89) based on adverse events cluster analysis using VigiBase, the World Health Organization's international database of suspected adverse drug reactions. Their analysis also revealed a large number of reports with a pattern of adverse events, including headache, dizziness, fatigue, and syncope and that these symptoms overlapped those that were reported in cases from the safety signals (POTS, CRPS, and CFS) in previous studies.

\section{Epidemiological studies}

Souayah et al. (2011), using data from the United States Vaccine Adverse Event Reporting System during 2006-2009, identified 69 reports of Guillain-Barré syndrome (GBS) after quadrivalent HPV vaccination and estimated that the weekly reporting rate of postquadrivalent HPV vaccine GBS within the first 6 weeks (6.6 cases per 10 million) was higher than that of the general population $(0.65-2.57$ cases per 10 million). A large Scandinavian register-based cohort study comparing almost 300,000 cases (received at least one dose of the quadrivalent HPV vaccine) and 700,000 controls found increased risk ratios (RRs) for three autoimmune manifestations: Behçet's syndrome, Raynaud's disease, and type 1 diabetes (Arnheim-Dahlström, Pasternak, Svanström, Sparén, \& Hviid, 2013).

A large-scale, self-completed mail survey of adverse events experienced in 70,000 young women, the "Nagoya City Cervical Cancer Immunization Program Survey" (hereafter, referred to as "the Nagoya Survey"), was conducted in September, 2015. Nagoya City reported the totalized summary and presented the complete questionnaire survey data to the public. At present, these summary and complete data are disclosed and available at the website of Nagoya City (Health and Welfare Bureau, Nagoya City, 2016). Suzuki and Hosono (2018) reported that none of the reported symptoms were significantly associated with increased odds of them occurring after the administration of the HPV vaccine based on the results of the Nagoya Survey. The safety issue of the HPV vaccine is still a controversy. The aim of this study was to assess the safety of HPV vaccines by using data from the Nagoya Survey.

\section{Current status and issues}

Although numerous case reports have suggested that $\mathrm{HPV}$ vaccines can cause serious side-effects, as well as a number of safety signals that have emerged with HPV vaccination in epidemiological studies, these findings do not provide consistent evidence for a causal link. Despite the existence of independently clustered reports and safety signals, on November 26, 2015, the European Medicines Agency (2015) released a 40 page assessment report on the safety of HPV vaccines, which concluded that there was no evidence of an association between HPV vaccines and CRPS or POTS, based on the review carried out by the European Medicines Agency's Pharmacovigilance Risk Assessment Committee.

In Japan, after the suspension of the government's recommendation for HPV vaccination in June, 2013, the HPV vaccination rate in the target population plunged from $80 \%$ at its peak to $<1 \%$ (as of 2015 , $0.1 \%$ in 12 year olds; $0.7 \%$ in 13 year olds) (Ministry of Health, Labour \& Welfare, 2016a). As of February, 2016, 3.39 million teenage girls have been vaccinated in Japan (Ministry of Health, Labour \& Welfare, 2016b).

\section{METHODS}

\section{Data source and variable selection for the analyses}

The data source for this investigation was the dataset of the Nagoya Survey (Health \& Welfare Bureau, Nagoya City, 2016). According to Nagoya City, the study population consisted of women who were aged 15-21 years who were residents of Nagoya City. The questionnaire survey period was from September to November, 2015 and the response rate was $43.3 \%$. The original data of the 275 questions from the 30,793 respondents are disclosed as a set of PDF files on the website of Nagoya City. Professor Okumura of Mie University voluntarily converted the PDFs into comma-separated values (CSVs) and uploaded them onto his personal website (Okumura, 2018). The authors downloaded the CSV data from his website and selected eight items for the analyses: age, individual HPV vaccine administration, the brand name of the HPV vaccine that was administered, time of the first HPV vaccination, the 24 symptoms experienced during the questionnaire survey period, onset time of each symptom, currently having symptoms and frequency ("always" or "sometimes"), and consultation with a doctor for the symptom(s). The 
authors verified the accuracy of the data and confirmed that it was reliable for analysis.

\section{Determining the vaccinated cases and the unvaccinated controls}

By using binary answers ("yes"/"no") for the question on individual HPV vaccine administration, the respondents were categorized into the "vaccinated case" group or the "unvaccinated control" group. The respondents who checked both choices or did not answer the question were included in the "unclear" group. However, after examination of the unclear group, some respondents in this group were reclassified into the vaccinated case group because they clearly answered the time of HPV vaccination or because they responded "unclear" for two or three of the three questions about the correct time of vaccination for the three doses of HPV vaccine.

\section{Determining the events and elapsed time period from the first vaccination to symptom onset}

This study constructed 24 event variables for the analyses that corresponded to the 24 symptoms that were investigated in the survey by editing the binary answers of "yes" or "no" for the question on a certain symptom that was experienced during the questionnaire survey period. For the answers of "yes," it was judged that the respondent experienced the symptom, while for the answers of "no," it was judged that she did not experience it. If the respondent checked both answers or did not check either answer, it was judged that the respondent's event was "uncertain." However, some events were changed from "uncertain" to "experienced" when the experiences could be confirmed because the onset time of the symptom, currently experiencing the symptom, or consultation with a doctor for symptom(s) was clearly described.

Events were excluded in the vaccinated case group in which the first HPV vaccination was administered after the onset time of the symptom because the causes are antecedent to the consequences. Therefore, these records were treated as vaccinated cases with no symptom. Consequently, the questionnaire survey period was defined differently between the vaccinated cases and the unvaccinated controls: the questionnaire survey period for the vaccinated cases was restricted to the post-vaccination period, while the period for the unvaccinated controls was the complete period of the questionnaire survey period (from 12 years of age to the participant's age at September, 2015). Hereafter, the term "study period" is used instead of the term "questionnaire survey period" to refer to the periods that are common between the vaccinated cases and the unvaccinated controls in terms of the "risk period." The intervals between the time of the first HPV vaccination and the onset time of the symptom in each vaccinated case was calculated for the analyses.

\section{Statistical analyses}

The data were summarized with descriptive statistics as the mean with standard deviation (SD) and the median with the interquartile range and the crude incidence odds were compared for the events between the vaccinated and the unvaccinated groups by unadjusted odds ratios (ORs) with $95 \%$ CIs.

Possible associations between HPV vaccination and each symptom were explored by fitting two multiple logistic regression models (models 1 and 2) with different covariates to the data to estimate the adjusted ORs with $95 \%$ CIs. The covariates that were used in model 1 were "vaccination" and "age" and those in model 2 were "vaccination" and "study period." Furthermore, to explore the interaction effect of vaccination and study period on symptom experience, a multiple logistic regression was used in model 3 . The covariates that were used in model 3 were "vaccination," "study period," and the interaction covariate between vaccination and study period. A logistic regression also was used to test for an interaction between vaccination and age and for an interaction between vaccination and study period. The results of two-sided testing was shown if necessary with $P$-values, without adjusting for multiplicity. All the analyses were conducted by using $\mathrm{R}$ version 3.2.2 (R Core Team, 2015).

Of the 30,279 women whose data on HPV vaccination were available, the data on age were available for 29,846 women. These data were included in multiple logistic regression model 1 and the age-stratified analyses. Of these 29,846 women, the time of the first vaccination was available for 26,665 women, who were included in multiple logistic regression models 2 and 3.

The proportion of vaccinated cases varied according to age due to the change in Japanese public health policy regarding HPV vaccination. Thus, the impact of a healthy vaccine effect bias would have varied by age. The healthy vaccine effect is a form of selection bias in which healthier persons might be more likely to be vaccinated, leading to a subsequent decrease in the risk of adverse events after vaccination; this bias is more likely to occur the higher the vaccination rate (Fine \& Chen, 1992; Shrank, Patrick, \& Brookhart, 2011). Therefore, 
Table 1 Participants' characteristics

\begin{tabular}{|c|c|c|c|c|c|c|c|c|c|}
\hline & Variable & & & & $\mathrm{N}($ & & & & \\
\hline Birth year & Age (years) & & $\begin{array}{l}\text { nated } \\
1,034)\end{array}$ & & $\begin{array}{l}\text { cinated } \\
9245)\end{array}$ & & & $\begin{array}{r}\text { Tot } \\
(n=30\end{array}$ & 793) \\
\hline 2000 & 15 & 662 & $(14.6)$ & 3761 & $(82.8)$ & 121 & $(2.7)$ & 4544 & $(100)$ \\
\hline 1999 & 16 & 2123 & $(50.1)$ & 2038 & $(48.1)$ & 80 & (1.9) & 4241 & $(100)$ \\
\hline 1998 & 17 & 3158 & $(70.2)$ & 1260 & $(28.0)$ & 83 & $(1.8)$ & 4501 & $(100)$ \\
\hline 1997 & 18 & 3766 & $(84.0)$ & 663 & $(14.8)$ & 55 & $(1.2)$ & 4484 & $(100)$ \\
\hline 1996 & 19 & 3725 & $(88.0)$ & 452 & $(10.7)$ & 58 & (1.4) & 4235 & $(100)$ \\
\hline 1995 & 20 & 3749 & $(88.7)$ & 428 & $(10.1)$ & 50 & (1.2) & 4227 & $(100)$ \\
\hline 1994 & 21 & 3565 & $(86.9)$ & 496 & $(12.1)$ & 41 & $(1.0)$ & 4102 & $(100)$ \\
\hline Subtotal & & 20,748 & $(68.4)$ & 9098 & $(30.0)$ & 488 & (1.6) & 30,334 & $(100)$ \\
\hline Age unclea & & 286 & $(62.3)$ & 147 & $(32.0)$ & 26 & (5.7) & 459 & $(100)$ \\
\hline Total & & 21,034 & $(68.3)$ & 9245 & $(30.0)$ & 514 & (1.7) & 30,793 & $(100)$ \\
\hline Vaccine adm & tered: N (\%) & $\begin{array}{l}\text { Vaccinate } \\
(n=20,7\end{array}$ & & & & & & & \\
\hline Bivalent va & & 13,319 & $(64.2)$ & & & & & & \\
\hline Quadrivale & vaccine & 4214 & $(20.3)$ & & & & & & \\
\hline Unknown & & 2895 & $(14.0)$ & & & & & & \\
\hline No answer & & 320 & $(1.5)$ & & & & & & \\
\hline Total & & 20,748 & $(100.0)$ & & & & & & \\
\hline Age (years) & & & $\begin{array}{l}\text { nated } \\
0,748)\end{array}$ & $\begin{array}{r}\text { Un } \\
(n\end{array}$ & $\begin{array}{l}\text { cinated } \\
9098)\end{array}$ & & $(n=$ & $\begin{array}{l}\text { otal } \\
29,846)\end{array}$ & \\
\hline Minimum & & & .0 & & 5.0 & & & 5.0 & \\
\hline Maximum & & & .0 & & 1.0 & & & 1.0 & \\
\hline Mean (SD) & & 18.6 & $(1.7)$ & 16.5 & $(1.8)$ & & 18.0 & $(2.0)$ & \\
\hline Median (IC & & 19.0 & $(17.0-20.0)$ & 16.0 & $(15.0-17.0)$ & & 18.0 & (16.0-20 & \\
\hline Study period & ar) & & $\begin{array}{l}\text { nated } \\
7,567)\end{array}$ & $\begin{array}{r}\mathrm{Un} \\
(n\end{array}$ & $\begin{array}{l}\text { cinated } \\
9098)\end{array}$ & & & & \\
\hline Minimum & & & 0 & & 3.0 & & & & \\
\hline Maximum & & & 0 & & .0 & & & & \\
\hline Mean (SD) & & 3.9 & $(0.9)$ & 4.5 & $(1.8)$ & & & & \\
\hline Median (IC & & 4.0 & $(3.0-4.0)$ & 4.0 & $(3.0-5.0)$ & & & & \\
\hline
\end{tabular}

$\mathrm{IQR}$, interquartile range; SD, standard deviation.

when comparing vaccinated cases with unvaccinated controls in the 17-21 year old group, in which the proportion of vaccinated women was $>70 \%$, it was considered that the likelihood of a healthy vaccine effect bias was high. In contrast, the proportions of vaccinated women in the 15 - and 16 year old groups were $15 \%$ and $50 \%$, respectively; thus, it was assumed that the risk of the healthy vaccine effect bias was relatively low in these age groups. Additionally, the respondents in the 15-16 year old group had reached the age of the target population for HPV vaccination after the suspension of the government recommendation. Therefore, it was hypothesized that almost all the respondents in this age group did not receive HPV vaccination simply because they did not want to be vaccinated and not because of health issues, leading to the low vaccination rate $(15 \%)$. Almost all the unvaccinated controls in this age group were expected to be averagely healthy women.
Furthermore, most women in the vaccinated case group, irrespective of age, were generally considered to be healthy women because they were healthy vaccine users. In order to minimize the impact of healthy user bias, agestratified analyses (15-, 16-, 15-16-, and 17-21 year old groups) were carried out and the vaccinated cases in all age groups (15-21 year old group) were compared with the unvaccinated controls in the 15-16 year old group.

This is an analytical study using data from open data sources. For this type of study, formal consent is not required.

\section{RESULTS}

\section{Characteristics of the study population}

Table 1 summarizes the characteristics of all the participants involved in the present study. Overall, 30,793 
Table 2 Age-adjusted odds ratios (ORs) provided by model 1 for all age groups

\begin{tabular}{|c|c|c|c|c|c|c|c|c|c|c|c|c|}
\hline \multirow[b]{3}{*}{ No. } & \multirow[b]{3}{*}{ Symptom } & \multicolumn{2}{|c|}{ Vaccinated } & \multicolumn{2}{|c|}{ Unvaccinated } & \multicolumn{3}{|c|}{ Unadjusted } & \multicolumn{3}{|c|}{ Age-adjusted $^{\dagger}$} & \multirow[b]{3}{*}{$P^{\ddagger}$} \\
\hline & & \multirow{2}{*}{$\begin{array}{c}\text { Event } \\
(+)\end{array}$} & \multirow{2}{*}{$\begin{array}{c}\text { Event } \\
(-)\end{array}$} & \multirow{2}{*}{$\begin{array}{l}\text { Event } \\
(+)\end{array}$} & \multirow{2}{*}{$\begin{array}{l}\text { Event } \\
(-)\end{array}$} & \multirow[b]{2}{*}{ OR } & \multicolumn{2}{|c|}{$95 \%$ CI } & \multirow[b]{2}{*}{ OR } & \multicolumn{2}{|c|}{$95 \% \mathrm{CI}$} & \\
\hline & & & & & & & Lower & Upper & & Lower & Upper & \\
\hline 1 & $\begin{array}{l}\text { Menstrual } \\
\text { abnormality }\end{array}$ & 3603 & 17,001 & 2309 & 6696 & 0.61 & 0.58 & 0.65 & 0.55 & 0.52 & 0.59 & 0.03 \\
\hline 2 & Menorrhagia & 1142 & 19,427 & 560 & 8434 & 0.89 & 0.80 & 0.98 & 0.77 & 0.68 & 0.86 & 0.29 \\
\hline 3 & Arthralgia & 1163 & 19,411 & 720 & 8276 & 0.69 & 0.63 & 0.76 & 0.67 & 0.60 & 0.75 & 0.00 \\
\hline 4 & Severe headache & 1529 & 19,083 & 925 & 8097 & 0.70 & 0.64 & 0.76 & 0.66 & 0.60 & 0.73 & 0.00 \\
\hline 5 & Lassitude & 1831 & 18,775 & 1037 & 7984 & 0.75 & 0.69 & 0.81 & 0.64 & 0.59 & 0.71 & 0.00 \\
\hline 6 & Exhaustion & 1867 & 18,734 & 991 & 8028 & 0.81 & 0.74 & 0.88 & 0.71 & 0.64 & 0.77 & 0.00 \\
\hline 7 & $\begin{array}{l}\text { Impaired } \\
\text { consciousness }\end{array}$ & 1159 & 19,425 & 723 & 8294 & 0.68 & 0.62 & 0.75 & 0.67 & 0.60 & 0.75 & 0.00 \\
\hline 8 & Abnormal visual field & 324 & 20,256 & 172 & 8845 & 0.82 & 0.68 & 0.99 & 0.68 & 0.55 & 0.85 & 0.01 \\
\hline 9 & Severe photophobia & 720 & 19,881 & 356 & 8662 & 0.88 & 0.77 & 1.00 & 0.74 & 0.64 & 0.86 & 0.00 \\
\hline 10 & Reduced visual acuity & 919 & 19,670 & 794 & 8221 & 0.48 & 0.44 & 0.53 & 0.52 & 0.46 & 0.58 & 0.00 \\
\hline 11 & Dizziness & 1836 & 18,759 & 1089 & 7927 & 0.71 & 0.66 & 0.77 & 0.67 & 0.61 & 0.73 & 0.00 \\
\hline 12 & $\begin{array}{l}\text { Cold sensation in the } \\
\text { legs }\end{array}$ & 1775 & 18,807 & 1144 & 7873 & 0.65 & 0.60 & 0.70 & 0.55 & 0.50 & 0.60 & 0.06 \\
\hline 13 & Sleep disorder & 1226 & 19,372 & 692 & 8320 & 0.76 & 0.69 & 0.84 & 0.57 & 0.51 & 0.64 & 0.00 \\
\hline 14 & Hypersomnolence & 1936 & 18,632 & 1058 & 7955 & 0.78 & 0.72 & 0.85 & 0.69 & 0.63 & 0.76 & 0.00 \\
\hline 15 & Skin roughness & 1497 & 19,100 & 1062 & 7950 & 0.59 & 0.54 & 0.64 & 0.54 & 0.49 & 0.59 & 0.89 \\
\hline 16 & Hyperpnea & 536 & 20,075 & 335 & 8694 & 0.69 & 0.60 & 0.80 & 0.60 & 0.51 & 0.70 & 0.00 \\
\hline 17 & Memory impairment & 559 & 20,054 & 217 & 8805 & 1.13 & 0.97 & 1.33 & 0.87 & 0.72 & 1.04 & 0.00 \\
\hline 18 & Dyscalculia & 167 & 20,442 & 79 & 8940 & 0.92 & 0.71 & 1.21 & 0.61 & 0.45 & 0.83 & 0.00 \\
\hline 19 & Dyslexia & 386 & 20,224 & 181 & 8846 & 0.93 & 0.78 & 1.11 & 0.66 & 0.54 & 0.81 & 0.00 \\
\hline 20 & Involuntary movement & 175 & 20,436 & 58 & 8964 & 1.32 & 0.98 & 1.78 & 1.05 & 0.76 & 1.48 & 0.04 \\
\hline 21 & Walking disability & 65 & 20,540 & 22 & 8990 & 1.29 & 0.80 & 2.10 & 0.90 & 0.53 & 1.57 & 0.06 \\
\hline 22 & $\begin{array}{l}\text { Using a cane or } \\
\text { wheelchair }\end{array}$ & 26 & 20,581 & 16 & 8994 & 0.71 & 0.38 & 1.32 & 0.49 & 0.25 & 1.02 & 0.26 \\
\hline 23 & $\begin{array}{l}\text { Sudden attack of } \\
\text { muscle weakness }\end{array}$ & 253 & 20,340 & 100 & 8909 & 1.11 & 0.88 & 1.40 & 0.92 & 0.71 & 1.20 & 0.01 \\
\hline 24 & Weakness & 318 & 20,224 & 124 & 8862 & 1.12 & 0.91 & 1.38 & 1.05 & 0.83 & 1.34 & 0.06 \\
\hline
\end{tabular}

Logistic regression in model 1;

${ }^{*} P$-value: test for the interaction between vaccination and age.

CI, confidence interval.

women were included, comprising 21,034 vaccinated cases, 9245 unvaccinated controls (subtotal: 30,279), and 514 women for whom their vaccination status was unclear.

First, except for the 16 year old group, there was a significant imbalance in the numbers of vaccinated and unvaccinated women. When the proportions of the vaccinated women were compared stratified by age, the proportion in the 15 year old group $(14.6 \%)$ was far less than that of the 16 year old group $(50.1 \%)$ and the $17-21$ year old group $(>70 \%)$. Second, there were threefold more women who had been administered the bivalent HPV vaccine than the quadrivalent HPV vaccine. Third, the unvaccinated controls tended to be younger than the vaccinated cases. The mean (SD) age was 18.6 (1.7) years for the vaccinated cases and 16.5 (1.8) years for the unvaccinated controls. Finally, the mean study period for the vaccinated cases (3.9 years) was 0.6 years shorter than that of the unvaccinated controls (4.5 years).

Possible association between human papilloma virus vaccination and symptoms Unadjusted and age-adjusted odds ratios in all age groups

Table 2 shows the unadjusted and age-adjusted ORs for all 24 symptoms among the 29,846 women. The 
vaccinated cases were slightly more likely than the unvaccinated controls to have experienced symptoms of memory impairment (unadjusted OR: 1.13 [95\% CI: 0.97-1.33]), involuntary movement (OR: 1.32 [95\% CI: 0.98-1.78]), walking disability (OR: 1.29 [95\% CI: 0.80-2.10]), a sudden attack of muscle weakness (OR: 1.11 [95\% CI: 0.88-1.40]), and weakness (OR: 1.12 [95\% CI: 0.91-1.38]). Apart from these symptoms, the other symptoms demonstrated ORs of $<1$ and most of them were statistically significant. In contrast, the multivariate analysis with the multiple logistic regression in model 1 (adjusted for age) demonstrated that the ORs for the symptoms of involuntary movement and weakness were 1 (involuntary movement: OR: 1.05 [95\% CI: 0.76-1.48] and weakness: OR: 1.05 [95\% CI: 0.83-1.34]). Apart from these two symptoms, the other symptoms demonstrated ORs of $<1$ and most of them were statistically significant. These results suggest that there was no association between HPV vaccination and the symptoms.

When considering these age-adjusted results, two key assumptions of multiple linear regression model 1 should be noted; that is, linearity and similarity (no interaction among the covariates). First, logistic regression model 1 assumes linearity of the independent variables and $\log$ odds of event occurrence. There were, however, no linear or monotone associations between age and the events across different symptoms in the total cohort. That is, the event rates did not show a tendency to increase or decrease relative to an increase of age. Furthermore, a substantial difference was observed between the event rates in the older age groups (e.g. $\geq 17$ years or $\geq 18$ years) and those in the younger

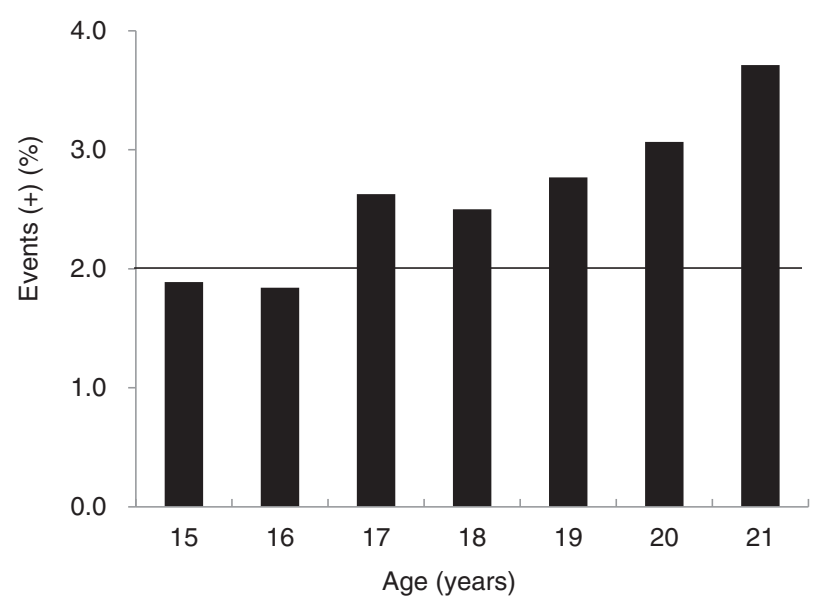

Figure 1 Age-stratified event rates in all age groups: Memory impairment.

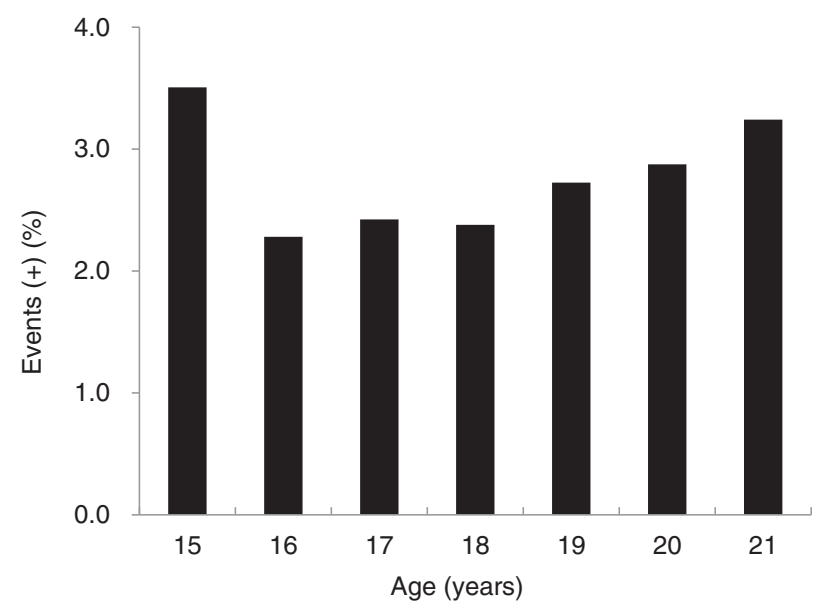

Figure 2 Age-stratified event rates in the vaccinated cases: Memory impairment.

age groups for several symptoms. For example, the event rates in the 15-16 year old group (or 15-17 year old group) were lower than those in the $\geq 17$ year old group (or $\geq 18$ year old group). A representative example of age-stratified event rates in which the event rates in the 15-16 year old group were substantially lower than those in the $\geq 17$ year old group is shown in Figure 1 . These findings suggest that not only with nonlinearity, but the population characteristics of the younger age groups, are substantially different from those of the older age groups related to discontinuity of the event rates.

Second, it should be noted that an age-adjusted rate is a method to make fairer comparisons between groups

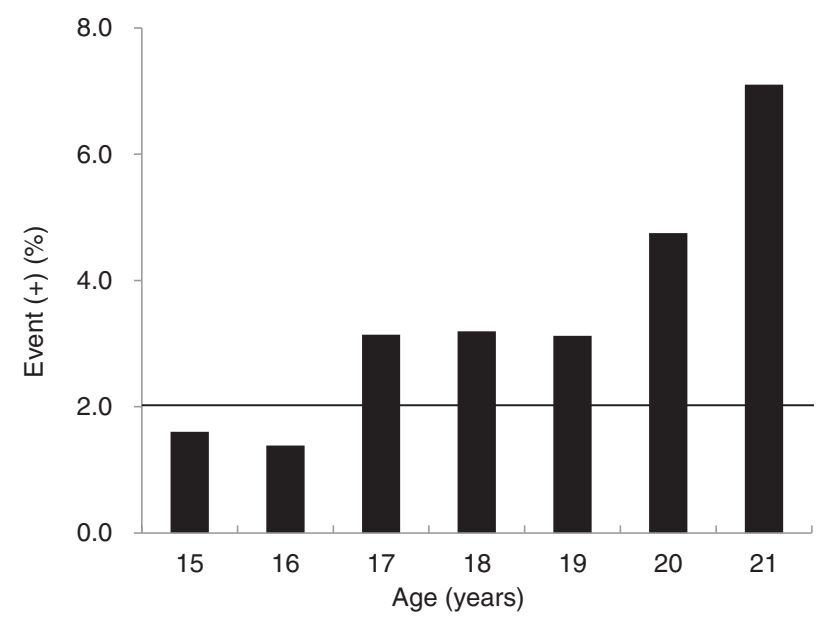

Figure 3 Age-stratified event rates in the unvaccinated controls: Memory impairment. 
Table 3 Study period-adjusted odds ratios (ORs) provided by model 2 in all age groups

\begin{tabular}{|c|c|c|c|c|c|c|c|c|c|c|c|c|}
\hline \multirow[b]{3}{*}{ No. } & \multirow[b]{3}{*}{ Symptom } & \multicolumn{2}{|c|}{ Vaccinated } & \multicolumn{2}{|c|}{ Unvaccinated } & \multicolumn{3}{|c|}{ Unadjusted } & \multirow{2}{*}{\multicolumn{3}{|c|}{$\frac{\text { Study period-adjusted }^{\dagger}}{95 \% \mathrm{CI}}$}} & \multirow[b]{3}{*}{$P^{\ddagger}$} \\
\hline & & \multirow{2}{*}{$\begin{array}{l}\text { Event } \\
(+)\end{array}$} & \multirow{2}{*}{$\begin{array}{c}\text { Event } \\
(-)\end{array}$} & \multirow{2}{*}{$\begin{array}{c}\text { Event } \\
(+)\end{array}$} & \multirow{2}{*}{$\begin{array}{l}\text { Event } \\
(-)\end{array}$} & \multirow[b]{2}{*}{ OR } & \multicolumn{2}{|c|}{$95 \%$ CI } & & & & \\
\hline & & & & & & & Lower & Upper & OR & Lower & Upper & \\
\hline 1 & $\begin{array}{l}\text { Menstrual } \\
\text { abnormality }\end{array}$ & 2686 & 14,759 & 2309 & 6696 & 0.53 & 0.50 & 0.56 & 0.55 & 0.52 & 0.59 & 0.90 \\
\hline 2 & Menorrhagia & 871 & 16,544 & 560 & 8434 & 0.79 & 0.71 & 0.88 & 0.85 & 0.76 & 0.95 & 0.56 \\
\hline 3 & Arthralgia & 894 & 16,529 & 720 & 8276 & 0.62 & 0.56 & 0.69 & 0.65 & 0.58 & 0.72 & 0.07 \\
\hline 4 & Severe headache & 1166 & 16,294 & 925 & 8097 & 0.63 & 0.57 & 0.69 & 0.67 & 0.61 & 0.74 & 0.54 \\
\hline 5 & Lassitude & 1396 & 16,058 & 1037 & 7984 & 0.67 & 0.61 & 0.73 & 0.72 & 0.66 & 0.79 & 0.00 \\
\hline 6 & Exhaustion & 1436 & 16,011 & 991 & 8028 & 0.73 & 0.67 & 0.79 & 0.77 & 0.71 & 0.85 & 0.01 \\
\hline 7 & $\begin{array}{l}\text { Impaired } \\
\text { consciousness }\end{array}$ & 903 & 16,532 & 723 & 8294 & 0.63 & 0.57 & 0.69 & 0.65 & 0.59 & 0.73 & 0.22 \\
\hline 8 & Abnormal visual field & 255 & 17,176 & 172 & 8845 & 0.76 & 0.63 & 0.93 & 0.85 & 0.69 & 1.04 & 0.17 \\
\hline 9 & Severe photophobia & 550 & 16,899 & 356 & 8662 & 0.79 & 0.69 & 0.91 & 0.89 & 0.77 & 1.02 & 0.40 \\
\hline 10 & Reduced visual acuity & 677 & 16,763 & 794 & 8221 & 0.42 & 0.38 & 0.46 & 0.42 & 0.38 & 0.47 & 0.29 \\
\hline 11 & Dizziness & 1417 & 16,025 & 1089 & 7927 & 0.64 & 0.59 & 0.70 & 0.66 & 0.61 & 0.72 & 0.01 \\
\hline 12 & $\begin{array}{l}\text { Cold sensation in the } \\
\text { legs }\end{array}$ & 1331 & 16,101 & 1144 & 7873 & 0.57 & 0.52 & 0.62 & 0.61 & 0.56 & 0.66 & 0.33 \\
\hline 13 & Sleep disorder & 940 & 16,508 & 692 & 8320 & 0.68 & 0.62 & 0.76 & 0.78 & 0.70 & 0.87 & 0.11 \\
\hline 14 & Hypersomnolence & 1493 & 15,925 & 1058 & 7955 & 0.70 & 0.65 & 0.77 & 0.75 & 0.69 & 0.82 & 0.14 \\
\hline 15 & Skin roughness & 1171 & 16,272 & 1062 & 7950 & 0.54 & 0.49 & 0.59 & 0.56 & 0.51 & 0.61 & 0.77 \\
\hline 16 & Hyperpnea & 408 & 17,049 & 335 & 8694 & 0.62 & 0.54 & 0.72 & 0.71 & 0.61 & 0.83 & 0.96 \\
\hline 17 & Memory impairment & 437 & 17,022 & 217 & 8805 & 1.04 & 0.88 & 1.23 & 1.23 & 1.03 & 1.47 & 0.00 \\
\hline 18 & Dyscalculia & 133 & 17,321 & 79 & 8940 & 0.87 & 0.66 & 1.15 & 1.13 & 0.83 & 1.54 & 0.00 \\
\hline 19 & Dyslexia & 291 & 17,163 & 181 & 8846 & 0.83 & 0.69 & 1.00 & 1.00 & 0.82 & 1.22 & 0.00 \\
\hline 20 & Involuntary movement & 150 & 17,307 & 58 & 8964 & 1.34 & 0.99 & 1.82 & 1.53 & 1.11 & 2.13 & 0.12 \\
\hline 21 & Walking disability & 54 & 17,397 & 22 & 8990 & 1.27 & 0.77 & 2.08 & 1.68 & 0.98 & 3.00 & 0.34 \\
\hline 22 & $\begin{array}{l}\text { Using a cane or } \\
\text { wheelchair }\end{array}$ & 21 & 17,433 & 16 & 8994 & 0.68 & 0.35 & 1.30 & 0.90 & 0.44 & 1.90 & 0.91 \\
\hline 23 & $\begin{array}{l}\text { Sudden attack of } \\
\text { muscle weakness }\end{array}$ & 208 & 17,234 & 100 & 8909 & 1.08 & 0.85 & 1.37 & 1.18 & 0.92 & 1.53 & 0.01 \\
\hline 24 & Weakness & 276 & 17,134 & 124 & 8862 & 1.15 & 0.93 & 1.43 & 1.21 & 0.97 & 1.52 & 0.22 \\
\hline
\end{tabular}

Logistic regression in model 2;

${ }^{*} P$-value: test for the interaction between vaccination and the study period.

CI, confidence interval.

with different age distributions. This method assumes that the effect of age on an event rate is similar between groups or shows no significant interaction among the covariates. However, this similarity was not observed between the vaccinated cases and the unvaccinated controls. For instance, a weak linear trend between age and event rates was observed only in the unvaccinated controls for some symptoms and was not observed in the vaccinated cases across different symptoms. Examples of each group were shown by using the data on memory impairment. Whereas, a linear trend is not observed in the vaccinated cases, it was observed in the unvaccinated controls (Figs 2 and 3), suggesting that the effect of age on the event rates is not similar between the two groups. Furthermore, as shown in Figure 1, the event rates in the 15-16 year old group were substantially lower than those in the $\geq 17$ year old group (Fig. 3 ).

Given these findings, it appeared that multiple logistic regression model 1 , with age as a covariate, was not appropriate for the data analysis in the present study. In fact, the test for the interaction between vaccination and age was statistically significant, except for distinct symptoms: menorrhagia $(P=0.29)$, a cold sensation in the legs $(P=0.06)$, skin roughness $(P=0.89)$, walking disability $(P=0.06)$, using a cane or wheelchair $(P=0.26)$, and weakness $(P=0.06)$ (Table 2$)$. These results further support that model 1 , with age as the covariate, was not appropriate. 


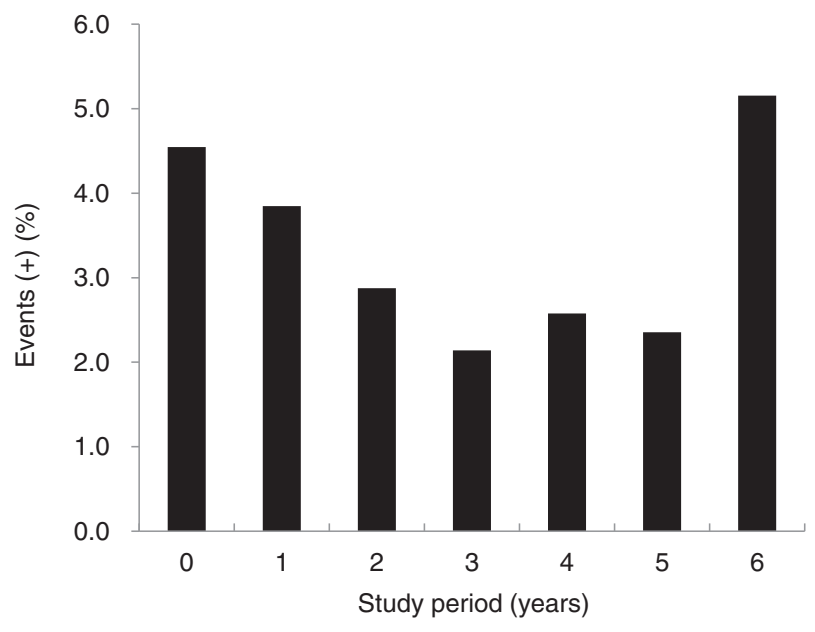

Figure 4 Study period-stratified event rates in the vaccinated cases: Memory impairment.

\section{Unadjusted and study period-adjusted odds ratios in all age groups}

From the above-mentioned findings, it was considered that an alternative covariate should be used in place of age for the logistic regression models. Therefore, "study period"-adjusted ORs were estimated in model 2. Table 3 shows the study period-adjusted ORs for all 24 symptoms among 26,665 women. The vaccinated cases were more likely than the unvaccinated controls to have experienced symptoms of memory impairment (OR: 1.23 [95\% CI: 1.03-1.47]), dyscalculia (OR: 1.13 [95\% CI: 0.83-1.54]), involuntary movement (OR: 1.53 [95\% CI: 1.11-2.13]), walking disability (OR: 1.68 [95\% CI: 0.98-3.00]), a sudden attack of muscle weakness (OR: 1.18 [95\% CI: 0.92-1.53]), and weakness (OR: 1.21 [95\% CI: 0.97-1.52]). Among these symptoms, the ORs of memory impairment and involuntary movement were statistically significant, suggesting that there is an association between HPV vaccination and these symptoms. The test for the interaction between vaccination and the study period was statistically significant for only seven symptoms (Table 3 ).

However, it should be noted that linearity was observed between event rates and the study period within only some symptoms. An example of a vaccinated case group was shown by using the data on memory impairment, in which a linear trend was not observed (Fig. 4). The study period-stratified event rates in the unvaccinated controls were the same as the agestratified event rates in the unvaccinated controls, as shown in Figure 3. Therefore, it is suggested that the effect of the study period on event rates is not similar between the two groups.

These findings suggest that logistic regression model 2 , with the study period as the covariate, does not always fit the data for the analyses and other approaches should be designed. Therefore, the results of both model 1 (age-adjusted) and model 2 (study periodadjusted) are considered as preliminary data.

Additionally, the study-period adjusted ORs were estimated in model 3. By fitting multiple logistic regression model 3 , of the seven symptoms in which the test for an interaction between vaccination and the study period was statistically significant, four symptoms demonstrated ORs that were $>1$ with statistical significance. They were the symptoms of memory impairment (OR: 3.59 [95\% CI: 2.05-6.25]), dyscalculia (OR: 4.37 [95\% CI: 1.63-11.61]), dyslexia that was characterized by a difficulty in reading and writing Chinese characters (hereinafter, referred to as "dyslexia") (OR: 2.82 [95\% CI: 1.46-5.39]), and a sudden attack of muscle weakness (OR; 3.16 [95\% CI: 1.42-6.96]), suggesting that there is an association between HPV vaccination and these symptoms (Table 4).

Unadjusted odds ratios provided by agestratified analyses (15-, 16-, 15-16-, and 17-21 year old groups)

The unadjusted ORs for the age-stratified analyses of all 24 symptoms among the 29,846 women are shown in Table 5 . In the 15 year old group, the ORs were significantly higher for the symptoms of memory impairment (OR: 2.23 [95\% CI: 1.37-3.63]), dyscalculia (OR: 2.30 [95\% CI: 1.01-5.24]), and dyslexia (OR: 1.75 [95\% CI: $1.01-3.03])$. In the 15-16 year old group, the ORs were significantly higher for the symptoms of memory impairment (OR: 1.70 [95\% CI: 1.24-2.33]), dyscalculia (OR: 1.77 [95\% CI: 1.00-3.13]), and involuntary movement (OR: 1.86 [95\% CI: 1.07-3.23]). In contrast, a subgroup analysis of the 17-21 year old group demonstrated the ORs of all symptoms were $<1$ and most were statistically significant.

In summary, although an association between HPV vaccination and symptoms was not observed in the population with a high healthy vaccine effect bias (e.g. 17-21 year old group), an association between HPV vaccination and some characteristic symptoms was observed in those populations with a low healthy vaccine effect bias (e.g. 15-, 16-, and 15-16 year old groups). These findings suggest that HPV vaccination 
Table 4 Study period-adjusted odds ratios (OR)s provided by model 3 in all age groups

\begin{tabular}{|c|c|c|c|c|c|c|c|c|c|c|c|c|}
\hline \multirow[b]{3}{*}{ No. } & \multirow[b]{3}{*}{ Symptom } & \multicolumn{2}{|c|}{ Vaccinated } & \multicolumn{2}{|c|}{ Unvaccinated } & \multicolumn{3}{|c|}{ Unadjusted } & \multirow{2}{*}{\multicolumn{3}{|c|}{$\begin{array}{c}\text { Study period-adjusted }^{\dagger} \\
95 \% \mathrm{CI} \\
\end{array}$}} & \multirow[b]{3}{*}{$P^{\ddagger}$} \\
\hline & & \multirow{2}{*}{$\begin{array}{c}\text { Event } \\
(+)\end{array}$} & \multirow{2}{*}{$\begin{array}{c}\text { Event } \\
(-)\end{array}$} & \multirow{2}{*}{$\begin{array}{l}\text { Event } \\
(+)\end{array}$} & \multirow{2}{*}{$\begin{array}{l}\text { Event } \\
(-)\end{array}$} & \multirow[b]{2}{*}{ OR } & \multicolumn{2}{|c|}{$95 \%$ CI } & & & & \\
\hline & & & & & & & Lower & Upper & OR & Lower & Upper & \\
\hline 1 & $\begin{array}{l}\text { Menstrual } \\
\text { abnormality }\end{array}$ & 2686 & 14,759 & 2309 & 6696 & 0.53 & 0.50 & 0.56 & 0.54 & 0.43 & 0.68 & 0.90 \\
\hline 2 & Menorrhagia & 871 & 16,544 & 560 & 8434 & 0.79 & 0.71 & 0.88 & 0.76 & 0.51 & 1.12 & 0.56 \\
\hline 3 & Arthralgia & 894 & 16,529 & 720 & 8276 & 0.62 & 0.56 & 0.69 & 0.89 & 0.62 & 1.28 & 0.07 \\
\hline 4 & Severe headache & 1166 & 16,294 & 925 & 8097 & 0.63 & 0.57 & 0.69 & 0.61 & 0.44 & 0.84 & 0.54 \\
\hline 5 & Lassitude & 1396 & 16,058 & 1037 & 7984 & 0.67 & 0.61 & 0.73 & 1.27 & 0.94 & 1.70 & 0.00 \\
\hline 6 & Exhaustion & 1436 & 16,011 & 991 & 8028 & 0.73 & 0.67 & 0.79 & 1.12 & 0.83 & 1.51 & 0.01 \\
\hline 7 & $\begin{array}{l}\text { Impaired } \\
\text { consciousness }\end{array}$ & 903 & 16,532 & 723 & 8294 & 0.63 & 0.57 & 0.69 & 0.81 & 0.56 & 1.16 & 0.22 \\
\hline 8 & Abnormal visual field & 255 & 17,176 & 172 & 8845 & 0.76 & 0.63 & 0.93 & 1.34 & 0.67 & 2.65 & 0.17 \\
\hline 9 & Severe photophobia & 550 & 16,899 & 356 & 8662 & 0.79 & 0.69 & 0.91 & 1.08 & 0.66 & 1.74 & 0.40 \\
\hline 10 & Reduced visual acuity & 677 & 16,763 & 794 & 8221 & 0.42 & 0.38 & 0.46 & 0.34 & 0.23 & 0.51 & 0.29 \\
\hline 11 & Dizziness & 1417 & 16,025 & 1089 & 7927 & 0.64 & 0.59 & 0.70 & 0.98 & 0.73 & 1.30 & 0.01 \\
\hline 12 & $\begin{array}{l}\text { Cold sensation in the } \\
\text { legs }\end{array}$ & 1331 & 16,101 & 1144 & 7873 & 0.57 & 0.52 & 0.62 & 0.70 & 0.52 & 0.95 & 0.33 \\
\hline 13 & Sleep disorder & 940 & 16,508 & 692 & 8320 & 0.68 & 0.62 & 0.76 & 1.04 & 0.72 & 1.50 & 0.11 \\
\hline 14 & Hypersomnolence & 1493 & 15,925 & 1058 & 7955 & 0.70 & 0.65 & 0.77 & 0.93 & 0.69 & 1.24 & 0.14 \\
\hline 15 & Skin roughness & 1171 & 16,272 & 1062 & 7950 & 0.54 & 0.49 & 0.59 & 0.53 & 0.39 & 0.73 & 0.77 \\
\hline 16 & Hyperpnea & 408 & 17,049 & 335 & 8694 & 0.62 & 0.54 & 0.72 & 0.70 & 0.40 & 1.21 & 0.96 \\
\hline 17 & Memory impairment & 437 & 17,022 & 217 & 8805 & 1.04 & 0.88 & 1.23 & 3.59 & 2.05 & 6.25 & 0.00 \\
\hline 18 & Dyscalculia & 133 & 17,321 & 79 & 8940 & 0.87 & 0.66 & 1.15 & 4.37 & 1.63 & 11.61 & 0.00 \\
\hline 19 & Dyslexia & 291 & 17,163 & 181 & 8846 & 0.83 & 0.69 & 1.00 & 2.82 & 1.46 & 5.39 & 0.00 \\
\hline 20 & Involuntary movement & 150 & 17,307 & 58 & 8964 & 1.34 & 0.99 & 1.82 & 3.19 & 1.17 & 8.66 & 0.12 \\
\hline 21 & Walking disability & 54 & 17,397 & 22 & 8990 & 1.27 & 0.77 & 2.08 & 3.68 & 0.66 & 20.66 & 0.34 \\
\hline 22 & $\begin{array}{l}\text { Using a cane or } \\
\text { wheelchair }\end{array}$ & 21 & 17,433 & 16 & 8994 & 0.68 & 0.35 & 1.30 & 0.77 & 0.06 & 8.85 & 0.91 \\
\hline 23 & $\begin{array}{l}\text { Sudden attack of } \\
\text { muscle weakness }\end{array}$ & 208 & 17,234 & 100 & 8909 & 1.08 & 0.85 & 1.37 & 3.16 & 1.42 & 6.96 & 0.01 \\
\hline 24 & Weakness & 276 & 17,134 & 124 & 8862 & 1.15 & 0.93 & 1.43 & 1.83 & 0.90 & 3.70 & 0.22 \\
\hline
\end{tabular}

Logistic regression in model 3;

${ }^{*} P$-value: test for the interaction between vaccination and the study period.

CI, confidence interval.

could lead to significant side-effects, such as memory impairment, dyscalculia, and involuntary movement.

\section{Unadjusted odds ratios provided by analyses comparing the vaccinated cases in all age groups with the unvaccinated controls in the 15-16 year old group}

The unadjusted ORs of the events for all 24 symptoms among 26,517 women, comparing the vaccinated cases $(20,748$ women) in all age groups with the unvaccinated controls (5769 women) in the 15-16 year old group, are shown in Table 6 . The ORs were significantly higher for the symptoms of memory impairment (OR: 1.80 [95\% CI: 1.43-2.25]), dyscalculia (OR: 1.80 [95\% CI: 1.19-2.73]), dyslexia (OR: 1.36 [95\% CI: 1.06-1.73]), involuntary movement (OR: $1.82 \quad[95 \%$ CI: 1.21-2.73]), walking disability (OR: 2.02 [95\% CI: 1.01-4.06]), and a sudden attack of muscle weakness (OR: 1.39 [95\% CI: 1.03-1.88]).

\section{Elapsed time period from the first vaccination to symptom onset}

The mean and median number of months between the time of the first HPV vaccination and the onset time of the symptoms are presented in Table 7 . The elapsed time period from the first vaccination to symptom onset ranged from 0 to 114 months. The median number of months from the first vaccination to symptom onset for the cognitive disorders was 24.0 (memory impairment), 25.0 (dyscalculia), and 30.0 (dyslexia). 


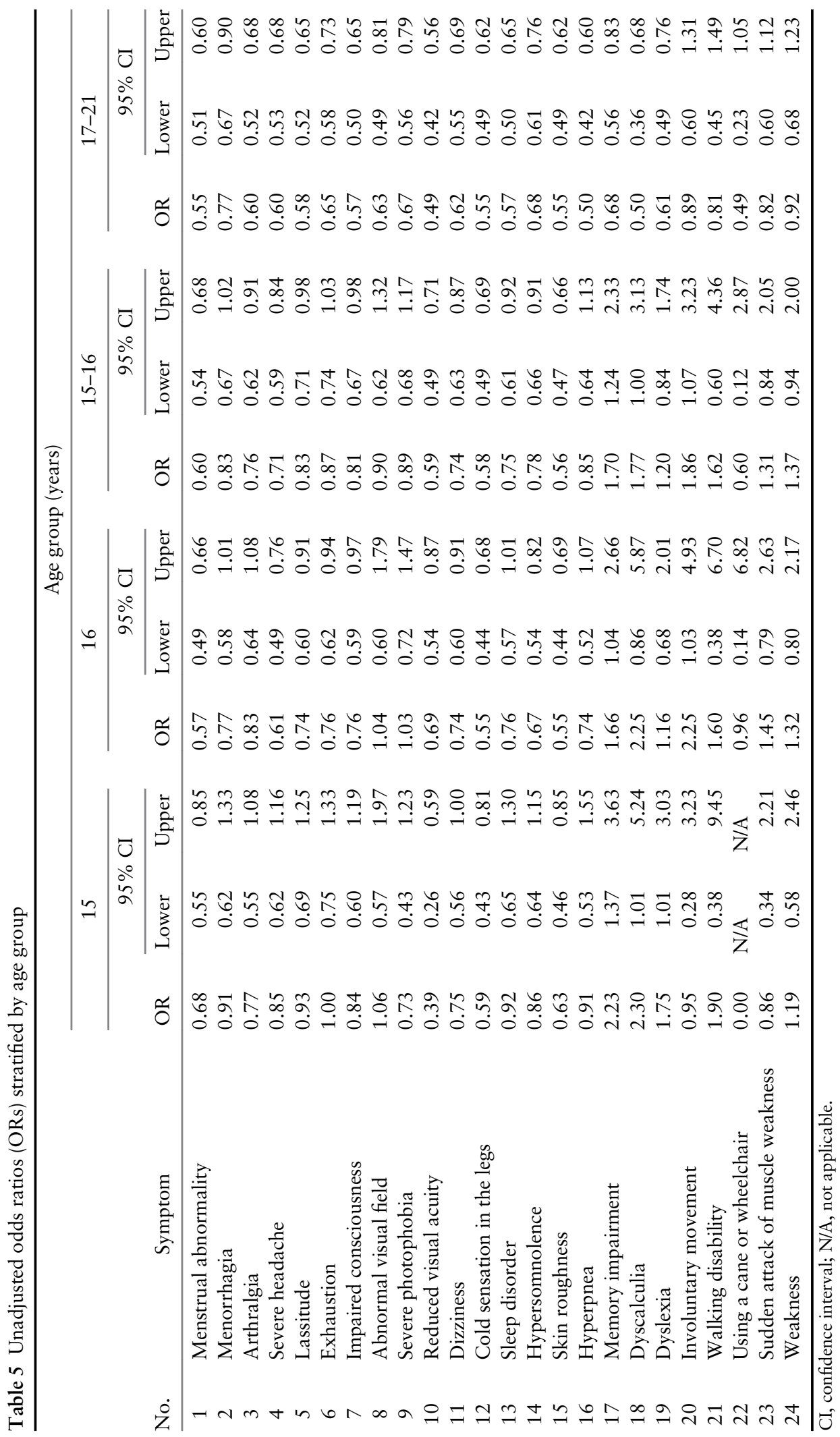


Table 6 Unadjusted odds ratios (ORs) comparing the vaccinated cases in all age groups with the unvaccinated controls in the 15-16 year old age group

\begin{tabular}{|c|c|c|c|c|c|c|c|c|}
\hline \multirow[b]{3}{*}{ No. } & \multirow[b]{3}{*}{ Symptom } & \multicolumn{2}{|c|}{ Vaccinated } & \multicolumn{2}{|c|}{ Unvaccinated } & \multicolumn{3}{|c|}{ Unadjusted } \\
\hline & & \multirow[b]{2}{*}{ Event $(+)$} & \multirow[b]{2}{*}{ Event (-) } & \multirow[b]{2}{*}{ Event $(+)$} & \multirow[b]{2}{*}{ Event (-) } & \multirow[b]{2}{*}{ OR } & \multicolumn{2}{|c|}{$95 \%$ CI } \\
\hline & & & & & & & Lower & Upper \\
\hline 1 & Menstrual abnormality & 3603 & 17,001 & 1399 & 4348 & 0.66 & 0.61 & 0.71 \\
\hline 2 & Menorrhagia & 1142 & 19,427 & 325 & 5414 & 0.98 & 0.86 & 1.11 \\
\hline 3 & Arthralgia & 1163 & 19,411 & 423 & 5320 & 0.75 & 0.67 & 0.85 \\
\hline 4 & Severe headache & 1529 & 19,083 & 537 & 5226 & 0.78 & 0.70 & 0.86 \\
\hline 5 & Lassitude & 1831 & 18,775 & 566 & 5195 & 0.90 & 0.90 & 0.99 \\
\hline 6 & Exhaustion & 1867 & 18,734 & 552 & 5204 & 0.94 & 0.85 & 1.04 \\
\hline 7 & Impaired consciousness & 1159 & 19,425 & 415 & 5339 & 0.77 & 0.68 & 0.86 \\
\hline 8 & Abnormal visual field & 324 & 20,256 & 90 & 5669 & 1.01 & 0.80 & 1.27 \\
\hline 9 & Severe photophobia & 720 & 19,881 & 184 & 5575 & 1.10 & 0.93 & 1.29 \\
\hline 10 & Reduced visual acuity & 919 & 19,670 & 519 & 5239 & 0.47 & 0.42 & 0.53 \\
\hline 11 & Dizziness & 1836 & 18,759 & 640 & 5119 & 0.78 & 0.71 & 0.86 \\
\hline 12 & Cold sensation in the legs & 1775 & 18,807 & 655 & 5104 & 0.74 & 0.67 & 0.81 \\
\hline 13 & Sleep disorder & 1226 & 19,372 & 359 & 5396 & 0.95 & 0.84 & 1.07 \\
\hline 14 & Hypersomnolence & 1936 & 18,632 & 622 & 5132 & 0.86 & 0.78 & 0.94 \\
\hline 15 & Skin roughness & 1497 & 19,100 & 652 & 5105 & 0.61 & 0.56 & 0.68 \\
\hline 16 & Hyperpnea & 536 & 20,075 & 168 & 5597 & 0.89 & 0.75 & 1.06 \\
\hline 17 & Memory impairment & 559 & 20,054 & 88 & 5673 & 1.80 & 1.43 & 2.25 \\
\hline 18 & Dyscalculia & 167 & 20,442 & 26 & 5737 & 1.80 & 1.19 & 2.73 \\
\hline 19 & Dyslexia & 386 & 20,224 & 80 & 5686 & 1.36 & 1.06 & 1.73 \\
\hline 20 & Involuntary movement & 175 & 20,436 & 27 & 5736 & 1.82 & 1.21 & 2.73 \\
\hline 21 & Walking disability & 65 & 20,540 & 9 & 5745 & 2.02 & 1.01 & 4.06 \\
\hline 22 & Using a cane or wheelchair & 26 & 20,581 & 7 & 5745 & 1.04 & 0.45 & 2.39 \\
\hline 23 & Sudden attack of muscle weakness & 253 & 20,340 & 51 & 5701 & 1.39 & 1.03 & 1.88 \\
\hline 24 & Weakness & 318 & 20,224 & 70 & 5666 & 1.27 & 0.98 & 1.65 \\
\hline
\end{tabular}

CI, confidence interval.

The median number of months for movement disorders was 20.5 (involuntary movement), 14.0 (walking disability), 17.0 (using a cane or wheelchair), 19.5 (a sudden attack of muscle weakness), and 17.0 (weakness). The median number of months for the cognitive disorders was $\sim 10$ months longer than those for the movement disorders.

\section{DISCUSSION}

\section{Adverse events following human papilloma virus vaccination \\ Healthy user bias, another form of selection bias, and the effect of an imbalance in the study period}

The unadjusted ORs were $<1$ for almost all the symptoms that were common in the adolescents, such as menstrual abnormality, lassitude, and dizziness, suggesting that HPV vaccination can reduce the risk of symptoms.
However, two types of hypotheses concerning these relatively low ORs can be made. First, one possible explanation for these findings is the healthy vaccine effect bias (Fine \& Chen, 1992; Shrank, Patrick, \& Brookhart, 2011). These common symptoms are more prone to the healthy vaccine effect. For instance, young women in better health might be more likely to be vaccinated and women in worse health might be less likely to receive HPV vaccination. Therefore, events in the vaccinated group might be underestimated, whereas those in the unvaccinated group might be overestimated. Consequently, when comparing the vaccinated cases with the unvaccinated controls, the ORs might be underestimated. As mentioned above in the section of statistical analyses, the healthy vaccine effect bias is more likely to occur the higher the vaccination rate. In fact, the ORs were $<1$ for all symptoms in the 17-21 year old group and most were statistically significant. That is, the influence of the healthy vaccine effect bias was remarkably observed in the analyses of the 17-21 year old group with high vaccination coverage $(>70 \%)$. 
Table 7 Elapsed time period from the first vaccination to symptom onset

\begin{tabular}{|c|c|c|c|c|c|c|c|c|c|}
\hline No. & Symptom & $\mathrm{n} 1^{\dagger}$ & $\mathrm{n} 2^{*}$ & Min. & Max. & Mean & $(\mathrm{SD})$ & Median & (IQR) \\
\hline 1 & Menstrual abnormality & 3603 & 1572 & 0 & 113 & 21.7 & $(16.1)$ & 19.0 & $(8.0-33.0)$ \\
\hline 2 & Menorrhagia & 1142 & 511 & 0 & 60 & 21.7 & $(15.7)$ & 19.0 & $(8.0-34.0)$ \\
\hline 3 & Arthralgia & 1163 & 500 & 0 & 63 & 18.2 & $(16.4)$ & 14.0 & $(3.1-31.0)$ \\
\hline 4 & Severe headache & 1529 & 646 & 0 & 64 & 20.6 & (15.6) & 18.0 & $(7.0-31.0)$ \\
\hline 5 & Lassitude & 1831 & 707 & 0 & 114 & 19.6 & $(15.7)$ & 17.0 & $(6.0-30.0)$ \\
\hline 6 & Exhaustion & 1867 & 742 & 0 & 114 & 21.7 & $(15.8)$ & 20.0 & $(8.0-33.0)$ \\
\hline 7 & Impaired consciousness & 1159 & 439 & 0 & 64 & 20.8 & $(15.8)$ & 17.0 & $(7.0-32.0)$ \\
\hline 8 & Abnormal visual field & 324 & 148 & 0 & 57 & 22.5 & $(15.8)$ & 20.0 & $(9.0-33.0)$ \\
\hline 9 & Severe photophobia & 720 & 261 & 0 & 64 & 23.1 & $(16.7)$ & 21.0 & $(8.0-37.0)$ \\
\hline 10 & Reduced visual acuity & 919 & 479 & 0 & 63 & 20.7 & $(14.7)$ & 18.0 & $(9.0-30.0)$ \\
\hline 11 & Dizziness & 1836 & 809 & 0 & 64 & 22.1 & $(15.8)$ & 20.0 & $(9.0-35.0)$ \\
\hline 12 & Cold sensation in the legs & 1775 & 384 & 0 & 52 & 15.1 & $(11.9)$ & 14.0 & $(4.0-22.0)$ \\
\hline 13 & Sleep disorder & 1226 & 494 & 0 & 113 & 28.1 & $(17.7)$ & 27.0 & $(13.0-42.8)$ \\
\hline 14 & Hypersomnolence & 1936 & 696 & 0 & 60 & 23.1 & $(15.3)$ & 21.0 & $(11.0-35.0)$ \\
\hline 15 & Skin roughness & 1497 & 739 & 0 & 60 & 25.0 & $(16.0)$ & 24.0 & $(11.0-38.0)$ \\
\hline 16 & Hyperpnea & 536 & 303 & 0 & 69 & 23.0 & $(15.6)$ & 21.0 & $(10.0-34.0)$ \\
\hline 17 & Memory impairment & 559 & 250 & 0 & 63 & 23.5 & $(16.1)$ & 24.0 & $(8.0-35.0)$ \\
\hline 18 & Dyscalculia & 167 & 76 & 0 & 54 & 23.3 & $(16.3)$ & 25.0 & $(7.8-35.0)$ \\
\hline 19 & Dyslexia & 386 & 154 & 0 & 60 & 28.9 & $(16.0)$ & 30.0 & $(16.0-41.5)$ \\
\hline 20 & Involuntary movement & 175 & 96 & 0 & 61 & 23.0 & $(16.3)$ & 20.5 & $(9.0-36.5)$ \\
\hline 21 & Walking disability & 65 & 41 & 0 & 55 & 17.6 & $(15.8)$ & 14.0 & $(5.0-25.0)$ \\
\hline 22 & Using a cane or wheelchair & 26 & 15 & 1 & 54 & 21.3 & $(17.4)$ & 17.0 & $(7.0-30.0)$ \\
\hline 23 & Sudden attack of muscle weakness & 253 & 118 & 0 & 56 & 21.9 & $(16.1)$ & 19.5 & $(7.3-35.0)$ \\
\hline 24 & Weakness & 318 & 170 & 0 & 57 & 20.7 & $(16.6)$ & 17.0 & $(6.0-35.0)$ \\
\hline
\end{tabular}

${ }^{\dagger}$ Number of patients with symptoms;

* the number of patients of which the onset time was available.

$\mathrm{CI}$, confidence interval; IQR, interquartile range; SD, standard deviation.

Second, a focus on the difference in the study period between the vaccinated cases and the unvaccinated controls should be considered. As described in the Methods section, the study period was restricted for the vaccinated cases to the post-vaccination period (range: 0-6 years) and the study period was defined for the unvaccinated controls as the complete time period of the questionnaire survey (from 12 years of age to the participant's age at September, 2015; range: 3-9 years). Consequently, the mean study period for the vaccinated cases was shorter than that for the unvaccinated controls. As a result of this difference, the event rates of the vaccinated cases were expected to be relatively underestimated, compared to those of the unvaccinated controls.

\section{Multivariate analysis: Age-adjustment and study period adjustment}

In contrast to the common symptoms in adolescents, the unadjusted ORs were $>1$ for distinct symptoms, including memory impairment, involuntary movement, walking disability, a sudden attack of muscle weakness, and weakness (Tables 2 and 3). Moreover, in the multivariate analysis, the study period-adjusted ORs for memory impairment, dyscalculia, involuntary movement, walking disability, a sudden attack of muscle weakness, and weakness were $>1$ and the ORs for memory impairment and involuntary movement were statistically significant, although they were not adjusted for multiplicity (Table 3). These findings are consistent with those of Yokota et al. (2015), who proposed the assumption that the HPV vaccine might develop hypothalamic damage, resulting in the onset of cognitive impairment or movement disorders.

In general, epidemiological research uses age adjustment to reduce the effect of having older participants in one group, compared to another group that has younger participants. However, an alternative covariate "study period" (defined by the postvaccination period for the vaccinated cases and the complete period of the questionnaire survey period for the unvaccinated controls) was considered, apart from age. 
When conducting a logistic regression analysis in the model without an interaction, there was a need to confirm which of the following assumptions were made in the analysis of the data from the study: (i) the covariate (age or study period) can be a confounder: (ii) the distribution of the covariate differs between the two groups (vaccinated cases and unvaccinated controls); (iii) the linearity between the covariate and events and similarity between the vaccinated cases and the unvaccinated controls are observed; and (iv) the test for an interaction between vaccination and the covariate is not statistically significant.

As for age adjustment, the data from the present study met only assumption (ii). With respect to a confounder (assumption (i)), the data did not meet the assumption. That is because, considering the participants in the present study are young women ranging in age from 15 to 21 years, it is unnatural that the risk of the disease is naturally higher in the older participants, compared to the younger ones, in terms of the target symptoms in the study. As mentioned above in the
Results section, there was neither a linear association between age and the event rates nor a similar effect of age on an event between the vaccinated cases and the unvaccinated controls. Furthermore, the test for the interaction between vaccination and age was statistically significant for almost all of the symptoms. These results supported the concept that the logistic regression model with age as the only covariate did not fit the data of this study. This is thought to explain why almost all the symptoms demonstrated ORs of $<1$ and most of them were statistically significant.

In contrast, the covariate "study period" can be a confounder because it refers to the risk period in which the event (the experience of symptom) occurs. That is, the longer the risk period, the more likely the participants are to have experienced symptoms. The distribution of the study period differed between the vaccinated cases and the unvaccinated controls. There was no linear association between the study period and event rates and no similar effect of the study period on an event between the vaccinated cases and the unvaccinated

Table 8 Age-standardized risk ratios (RRs) in all age groups

\begin{tabular}{|c|c|c|c|c|c|c|c|c|c|c|c|}
\hline \multirow[b]{3}{*}{ No. } & \multirow[b]{3}{*}{ Symptom } & \multicolumn{2}{|c|}{ Vaccinated } & \multicolumn{2}{|c|}{ Unvaccinated } & \multicolumn{3}{|c|}{ Unadjusted } & \multicolumn{3}{|c|}{ Age-standardized } \\
\hline & & \multirow{2}{*}{$\begin{array}{l}\text { Event } \\
(+)\end{array}$} & \multirow{2}{*}{$\begin{array}{c}\text { Event } \\
(-)\end{array}$} & \multirow{2}{*}{$\begin{array}{l}\text { Event } \\
(+)\end{array}$} & \multirow{2}{*}{$\begin{array}{c}\text { Event } \\
(-)\end{array}$} & \multirow[b]{2}{*}{$\mathrm{RR}$} & \multicolumn{2}{|c|}{$95 \% \mathrm{CI}$} & \multirow[b]{2}{*}{$\mathrm{RR}$} & \multicolumn{2}{|c|}{$95 \% \mathrm{CI}$} \\
\hline & & & & & & & Lower & Upper & & Lower & Upper \\
\hline 1 & Menstrual abnormality & 3603 & 17,001 & 2309 & 6696 & 0.68 & 0.65 & 0.71 & 0.63 & 0.60 & 0.67 \\
\hline 2 & Menorrhagia & 1142 & 19,427 & 560 & 8434 & 0.89 & 0.81 & 0.98 & 0.78 & 0.69 & 0.88 \\
\hline 3 & Arthralgia & 1163 & 19,411 & 720 & 8276 & 0.71 & 0.65 & 0.77 & 0.63 & 0.57 & 0.71 \\
\hline 4 & Severe headache & 1529 & 19,083 & 925 & 8097 & 0.72 & 0.67 & 0.78 & 0.64 & 0.58 & 0.70 \\
\hline 5 & Lassitude & 1831 & 18,775 & 1037 & 7984 & 0.77 & 0.72 & 0.83 & 0.65 & 0.59 & 0.71 \\
\hline 6 & Exhaustion & 1867 & 18,734 & 991 & 8028 & 0.82 & 0.77 & 0.89 & 0.71 & 0.65 & 0.78 \\
\hline 7 & Impaired consciousness & 1159 & 19,425 & 723 & 8294 & 0.70 & 0.64 & 0.77 & 0.65 & 0.58 & 0.72 \\
\hline 8 & Abnormal visual field & 324 & 20,256 & 172 & 8845 & 0.83 & 0.69 & 0.99 & 0.65 & 0.52 & 0.82 \\
\hline 9 & Severe photophobia & 720 & 19,881 & 356 & 8662 & 0.89 & 0.78 & 1.00 & 0.67 & 0.57 & 0.78 \\
\hline 10 & Reduced visual acuity & 919 & 19,670 & 794 & 8221 & 0.51 & 0.46 & 0.56 & 0.51 & 0.45 & 0.57 \\
\hline 11 & Dizziness & 1836 & 18,759 & 1089 & 7927 & 0.74 & 0.69 & 0.79 & 0.67 & 0.61 & 0.73 \\
\hline 12 & Cold sensation in the legs & 1775 & 18,807 & 1144 & 7873 & 0.68 & 0.63 & 0.73 & 0.57 & 0.52 & 0.62 \\
\hline 13 & Sleep disorder & 1226 & 19,372 & 692 & 8320 & 0.78 & 0.71 & 0.85 & 0.59 & 0.52 & 0.65 \\
\hline 14 & Hypersomnolence & 1936 & 18,632 & 1058 & 7955 & 0.80 & 0.75 & 0.86 & 0.70 & 0.64 & 0.76 \\
\hline 15 & Skin roughness & 1497 & 19,100 & 1062 & 7950 & 0.62 & 0.57 & 0.66 & 0.58 & 0.52 & 0.63 \\
\hline 16 & Hyperpnea & 536 & 20,075 & 335 & 8694 & 0.70 & 0.61 & 0.80 & 0.54 & 0.46 & 0.64 \\
\hline 17 & Memory impairment & 559 & 20,054 & 217 & 8805 & 1.13 & 0.97 & 1.32 & 0.81 & 0.67 & 0.97 \\
\hline 18 & Dyscalculia & 167 & 20,442 & 79 & 8940 & 0.93 & 0.71 & 1.21 & 0.59 & 0.43 & 0.82 \\
\hline 19 & Dyslexia & 386 & 20,224 & 181 & 8846 & 0.93 & 0.78 & 1.11 & 0.63 & 0.51 & 0.79 \\
\hline 20 & Involuntary movement & 175 & 20,436 & 58 & 8964 & 1.32 & 0.98 & 1.78 & 0.90 & 0.63 & 1.29 \\
\hline 21 & Walking disability & 65 & 20,540 & 22 & 8990 & 1.29 & 0.80 & 2.09 & 0.74 & 0.41 & 1.31 \\
\hline 22 & Using a cane or wheelchair & 26 & 20,581 & 16 & 8994 & 0.71 & 0.38 & 1.32 & 0.40 & 0.19 & 0.82 \\
\hline 23 & $\begin{array}{l}\text { Sudden attack of muscle } \\
\text { weakness }\end{array}$ & 253 & 20,340 & 100 & 8909 & 1.11 & 0.88 & 1.39 & 0.78 & 0.58 & 1.03 \\
\hline 24 & Weakness & 318 & 20,224 & 124 & 8862 & 1.12 & 0.91 & 1.38 & 0.94 & 0.72 & 1.22 \\
\hline
\end{tabular}

CI, confidence interval. 
controls. The test for an interaction between vaccination and the study period was not statistically significant, except for seven symptoms (Table 3). As abovementioned, the logistic regression model with the study period as a covariate did not always fit the data from the present study. However, it can at least be stated that, in the case of the logistic regression, it appears more reasonable to assume that the study period is more appropriate than age as a covariate.

Suzuki and Hosono (2018) reported the age-adjusted ORs of the association of vaccination and the occurrence of symptoms as primary outcomes, in which almost all the symptoms demonstrated ORs of $<1$ and most of them were statistically significant. These results should be interpreted with caution. The reason is as follows. They described that age confounded the association between HPV vaccination and the reported symptoms. Therefore, they decided all the analyses should be age-adjusted, although they did not provide any details of the methods, such as considering and examining the confounders or exploring the data distribution.

As a supplementary analysis, the possible associations between HPV vaccination and each symptom were explored by using standardization with the reference group of the whole participants to estimate the agestandardized RR with 95\% CIs (Sato, 1994). Table 8 summarizes the age-standardized RRs for all 24 symptoms among 29,846 women. All the symptoms demonstrated RRs of $<1$ and most of them were statistically significant. These findings raise the possibility that there was no association between HPV vaccination and the symptoms (Table 8). In this regard, however, it is noted that the RR varied and did not show the same direction across the age strata for almost all the symptoms; hence, standardization does not fit the data from the present study.

\section{Age-stratified analysis considering the effect of the healthy user}

Most of the vaccinated women in all age groups generally were considered to be healthy women because they were healthy vaccine users. The women in the 15-16 year old group had reached the age of the target population for HPV vaccination after suspension of the government recommendation. Thus, almost all the women in this age group were expected to be unvaccinated simply because they did not want to be vaccinated, not because of health issues. Given this information, it was assumed that the unvaccinated controls in the 15-16 year old group were generally healthy. In order to minimize the impact of the healthy user bias, the vaccinated cases in all age groups were compared with the unvaccinated controls in the 15-16 year old group. The ORs were significantly higher for the symptoms of memory impairment, dyscalculia, dyslexia, involuntary movement, walking disability, and a sudden attack of muscle weakness. These findings suggested that HPV vaccination might cause significant health problems, which can impair learning and have a negative impact on daily life.

\section{Limitations of the present study and suggestions for further research}

The validity of the findings from the questionnaire surveys is dependent on adequate response rates. The response rate of the Nagoya Survey was moderate, at $43 \%(30,793 / 71,177)$; thus, the findings of the present study should be considered in light of this limitation. Moreover, another potential limitation of the present study is that differential misreporting or misclassification bias, as well as the characteristic symptom development in a multilayered manner, were not evaluated.

Further large-scale and well-designed (careful consideration should be given to the characteristics of postHPV vaccination symptoms) cohort studies are warranted to confirm the causal relationship between HPV vaccination and the occurrence of possible adverse events, as suggested by the current exploratory analyses.

\section{CONCLUSION}

Based on this analysis using data from the Nagoya Survey, a possible association between HPV vaccination and distinct symptoms, such as cognitive impairment or movement disorders, exists. A consistent causal relationship between HPV vaccination and these symptoms remains uncertain. However, given the seriousness of the symptoms, the authors believe that a more comprehensive and large-scale study is essential to confirm the safety of HPV vaccination.

\section{ACKNOWLEDGMENTS}

The authors wish to thank Naohito Fukui (EP-CRSU Company, Ltd., Tokyo, Japan) for assistance with analyzing the data with $\mathrm{R}$. 


\section{DISCLOSURE}

The authors declare no conflict of interest.

\section{AUTHOR CONTRIBUTIONS}

Y. Y. was involved in the conception, design, and analysis of this study and drafted the manuscript; H. T. supervised the whole study process and critically reviewed the manuscript. Both authors read and approved the final manuscript.

\section{REFERENCES}

Arnheim-Dahlström, L., Pasternak, B., Svanström, H., Sparén, P. \& Hviid, A. (2013). Autoimmune, neurological, and venous thromboembolic adverse events after immunization of adolescent girls with quadrivalent human papillomavirus vaccine in Denmark and Sweden: Cohort study. BMJ, 347, f5906.

Blitshteyn, S. (2014). Postural tachycardia syndrome following human papillomavirus vaccination. European Journal of Neurology, 21, 135-139.

Brinth, L., Theibel, A. C., Pors, K. \& Mehlsen, J. (2015). Suspected side effects to the quadrivalent human papilloma vaccine. Danish Medical Journal, 62, A5064.

Chandler, R. E., Juhlin, K., Fransson, J., Caster, O., Edwards, I. R. \& Norén, G. N. (2017). Current safety concerns with human papillomavirus vaccine: A cluster analysis of reports in VigiBase ${ }^{\circledR}$. Drug Safety, 40, 81-90.

European Medicines Agency. (2015). Assessment report, review under article 20 of regulation (EC) no 726/2004. London: European Medicines Agency. [Cited 28 Sep 2018.] Available from URL: http://www.ema.europa. eu/docs/en_GB/document_library/Referrals_document/ HPV_vaccines_20/Opinion_provided_by_Committee_for Medicinal_Products_for_Human_Use/WC500197129.pdf

Fine, P. E. \& Chen, R. T. (1992). Confounding in studies of adverse reactions to vaccines. American Journal of Epidemiology, 136, 121-135.

Health and Welfare Bureau, Nagoya City. (2016). Nagoya City cervical cancer immunization program survey results. [Cited 28 Sep 2018.] Available from URL: http://www. city.nagoya.jp/kenkofukushi/page/0000088972.html (in Japanese).

Kinoshita, T., Abe, R., Hineno, A., Tsunekawa, K., Nakane, S. \& Ikeda, S. (2014). Peripheral sympathetic nerve dysfunction in adolescent Japanese girls following immunization with the human papillomavirus vaccine. Internal Medicine, 53, 2185-2200.

Markowitz, L. E., Dunne, E. F., Saraiya, M., Lawson, H. W., Chesson, H. \& Unger, E. R. (2007). Quadrivalent human papillomavirus vaccine recommendations of the advisory committee on immunization practices (ACIP). Morbidity and Mortality Weekly Report (MMWR) Recommendations and Reports, 56(RR-2), 1-24.

Ministry of Health, Labour and Welfare. (2013). Notification from the Ministry of Health, Labour and Welfare (MHLW) on routine vaccination programme of HPV vaccine [Cited 28 Sep 2018.] Available from URL: http:// www.mhlw.go.jp/bunya/kenkou/kekkaku-kansenshou28/ (in Japanese).

Ministry of Health, Labour and Welfare. (2016a). 'National cumulative vaccination coverage by age' from the reference document of document no. 4 "National epidemiological survey" distributed at the meeting of the Joint Committee of Health Science Council, Sub-committee of Adverse Drug Reactions to Vaccines and Pharmaceutical Affairs and Food Sanitation Council, Sub-committee on Safety of Drugs. [Cited 28 Sep 2018.] Available from URL: http://www. mhlw.go.jp/stf/shingi2/0000147015.html (in Japanese).

Ministry of Health, Labour and Welfare. (2016b). Documents 16 and 17 distributed at the meeting of the Joint Committee of Health Science Council, Sub-committee of Adverse Drug Reactions to Vaccines and Pharmaceutical Affairs and Food Sanitation Council, Sub-committee on Safety of Drugs. [Cited 28 Sep 2018.] Available from URL: http:// www.mhlw.go.jp/stf/shingi2/0000125164.html (in Japanese).

Nishioka, K., Yokota, S. \& Matsumoto, Y. (2014). Clinical features and preliminary diagnostic criteria of human papillomavirus vaccination associated with neuroimmunopathic syndrome (HANS). International Journal of Rheumatic Disease, 17(Suppl 2), 6.

Okumura, H. (2018). CSV data of Nagoya study. [Cited 28 Sep 2018.] Available from URL: https://oku.edu.mie-u. ac.jp/ okumura/stat/160629.html (in Japanese).

Ozawa, K., Hineno, A., Kinoshita, T., Ishihara, S. \& Ikeda, S. (2017). Suspected adverse effects after human papillomavirus vaccination: A temporal relationship between vaccine administration and the appearance of symptoms in Japan. Drug Safety, 40, 1219-1229.

R Core Team. (2015). R: A language and environment for statistical computing. Vienna: R Foundation for Statistical Computing Available from URL: https://www.Rproject.org.

Sato, T. (1994). Confounding and effect modification in epidemiologic studies. Proceedings of the Institute of Statistical Mathematics, 42, 83-101 (in Japanese).

Shrank, W. H., Patrick, A. R. \& Brookhart, M. A. (2011). Healthy user and related biases in observational studies of preventive interventions: A primer for physicians. Journal of General Internal Medicine, 26, 546-550.

Souayah, N., Michas-Martin, P. A., Nasar, A., Krivitskaya, N. \& Yacoub, H. A., Khan, H. et al. (2011). Guillain-Barré syndrome after Gardasil vaccination: Data from vaccine adverse event reporting system 2006-2009. Vaccine, 29, 886-889. 
Suzuki, S. \& Hosono, A. (2018). No association between HPV vaccine and reported post-vaccination symptoms in Japanese young women: Results of the Nagoya study. Papillomavirus Research, 5, 96-103.

World Health Organization. (2014). Human papillomavirus vaccines: WHO position paper. Weekly Epidemiological
Record, 89, 465-491. [Cited 28 Sep 2018.] Available from URL: http://www.who.int/wer/2014/wer8943/en/

Yokota, S., Kuroiwa, Y., Nakamura, I., Nakajima, T. \& Nishioka, K. (2015). General overview and discussion on HPV vaccine associated neuropathic syndrome. Japan Medical Journal, 4758, 46-53 (in Japanese). 